\title{
Detection of Active Mobile Phone in Exam Hall
}

\author{
Najla Aiman Nazari ${ }^{1}$, Ili Najaa Aimi Mohd Nordin ${ }^{1 *}$, Muhammad Rusydi Muhammad Razif ${ }^{1}$, \\ Noraishikin Zulkarnain ${ }^{2}$ and Nurulaqilla Khamis ${ }^{3}$
}

\author{
${ }^{1}$ Department of Electrical Engineering Technology, Faculty of Engineering Technology, Universiti Tun Hussein Onn \\ Malaysia, 84600 Pagoh, Johor, Malaysia. \\ ${ }^{2}$ Faculty of Engineering and Built Environment, Universiti Kebangsaan Malaysia, 43600 Bangi, Selangor, Malaysia. \\ ${ }^{3}$ Malaysia-Japan International Institute of Technology, Universiti Teknologi Malaysia, 54100 Kuala Lumpur, Wilayah \\ Persekutuan Kuala Lumpur, Malaysia
}

*Corresponding author: ilinajaa@uthm.edu.my

\begin{abstract}
The use of mobile phone as a cheating tool in the examination hall among students have considerably increased a burden to invigilators to ensure integrity in examination hall. Many active mobile phone detection schemes had been proposed as the solution to this problem. However, the detection system function in a small detection range of 1.5 to 2 meters from the detection circuit and does not distinguish various frequency bands of radio frequency signals. In order to have diverse range of RF mobile phone signals detection for alerting the invigilators of their specified monitoring region, antenna is proposed to be used. This is done by antenna design simulation using Computer Simulation Technology (CST) software. Two types of antenna; single-dipole antenna and multi-band dipole antenna are simulated to know the characteristics of VSWR, gain and total efficiency. From the simulation results, multi-band dipole antenna shows acceptable VSWR value which are approximate to $2 \mathrm{~V}$, gain is equal to $2.85 \mathrm{~dB}$ and total efficiency is equal to $2.484 \mathrm{~dB}$ for $2.4 \mathrm{GHz}$ signal. The results imply positive event that multi-band antenna can be a preferable tool in elaborating accurate RF signal detection of active mobile phone in examination hall.
\end{abstract}

Keywords: CST, mobile phone detection, multi-band antenna and single-dipole antenna.

Article History: received 4 September 2019; accepted 1 December 2019; published 24 December 2019.

(C) 2019 Penerbit UTM Press. All rights reserved

\section{INTRODUCTION}

Examination malpractice can be defined as a deliberate wrongdoing that is contrary to official examination rules and is purposed to place a candidate at an unfair advantage or disadvantage [1]. It is also defined as the way of the candidates to ensure they pass the examination without relying absolutely on his or her independent ability.

There are several types of known examination malpractice such as impersonation, physical assault, use of mercenaries and spying or sneaking. Spying and sneaking are considered as cheating in the exam [2]. Nowadays, due to the outrageous mobile phone application among youngsters, mobile phone is immorally used as a medium of cheating in the examination hall [3]-[5]. Year by year, this problem has been making it critical for the invigilators to maintain the integrity of the examination process [1], [6]. According to [7], cheating, using a mobile phone is the most popular way among the students by texting their friends for answers or by searching the information through the electronics notes and search engine.

To prevent this from happening, many mobile phones and jammers had been invented by the researchers in many forms of prototype. However, their prototype has limitation of about 1.5 meters to 2 meters of detection range. This has caused a problem for the invigilators to detect which area that the active mobile phone is present in a specific small range.
In order to widen the signal detection range, antenna is usually being used. The common types of antenna design are the microstrip antenna, single-dipole antenna and multi-band dipole antenna. Microstrip antenna consists of patch, substrate and ground plane. This antenna has various advantages such as simple to design, easy to modify according to needs, inexpensive and lightweight. Even so, it suits low bandwidth and low power application $[8,9]$.

Other type of antenna is single-dipole antenna, usually consist of two straight lines of the same length, lying on the same axis and separated by a small gap [10]. Dipole antenna in [11] is shown to have the maximum directivity. The directivity is very dependent on the antenna length.

Multi-band antenna can cover the frequency range of GSM, DCS, PCS, UMTS, Bluetooth, WLAN and WiMAX is proposed [12]. Multi-band antenna can be designed by using a single printed dipole incorporating Compact Resonant Cell (CRC) structures because CRC structures provide a simultaneous matching for different frequencies [13].

Considering the latest mobile phones are coming equipped with various frequency ranges, multi-band antenna and single-dipole antenna can be the best candidate to be employed in the detection system of active mobile phone in assisting the invigilators during examination sessions.

In this paper, two types of antenna, predicted to be able 
to extend the range of detection system coverage to GSM, $3 \mathrm{G}$ and Wifi were studied. It is predicted that the best antenna design analyzed in this paper able to improve the RF signal detection range of active mobile phone.

\section{METHODOLOGY}

Two types of antenna design were modeled and simulated using Computer Integrated Technology (CST) software to ensure that the antenna meets the ideal requirement before being used in the detection system.

Basically, before simulating an antenna design, the antenna frequency, length, width and thickness have to be decided. The specifications of those parameters are described in Section 2.1 and in Section 2.2. In this simulation, the time domain solver was used as it features a user-friendly interface and it is intended for transient analysis of 3-D structures. It also can read any userspecified excitation waveform and calculate the required transient response.

\subsection{Antenna Design and Structure}

The geometric and excitation parameter of the antennas are depending on the design. The antenna geometric characteristics such as beam width and main-lobe to sidelobe power ratio can be described by the mathematical expressions of radiation patterns [14].

Also, the directivity of the antenna that can be viewed from the far-field results can be related to the gain and the coverage. The higher antenna gain value, the more directive antenna radiation pattern become, which entailed a narrower beam width. Thus, the radius of detection coverage become smaller and vice versa [11].

\subsection{Numerical Method}

A multi-band dipole antenna and a dipole antenna were simulated in order to conclude the most efficient antenna in detecting the RF signal from an active mobile phone. Since the detection system aim for detecting any RF signal in 4-meter radius of coverage, it is important to ensure the power received by the antenna is just enough to detect signals within 4-meter radius of coverage, thus, the power received by the antenna can be calculated by using Free space path loss (FSPL) equation as in Equation (1) and the Friis equation as in Equation (2) [15, 16].

4-meter is assumed to be the distance from the transmitter, $D_{r}$ as in Equation (1). FSPL is calculated to know the value of loss in signal strength of an electromagnetic wave when no obstacles nearby to cause reflection or diffraction. FSPL exists in the form of attenuation that occurs during signal transmission over distance.

$$
F S P L=\left(\frac{4 \pi D_{r}}{\lambda}\right)^{2}=\left(\frac{4 \pi D_{r} f_{o}}{c}\right)^{2}
$$

where:

$\lambda$ is the signal wavelength (in meters),

$f_{o}$ is the signal frequency (in Hertz),

$D_{r}$ is the distance from the transmitter (in meters), and

$c$ is the speed of light in vacuum, $2.99792457 \times 10^{8}$ meters per second.
Friis equation is used to calculate the amount of power received comes from another antenna under ideal condition assumption [17]. Therefore, the ideal value of received power from the active mobile phone in the examination hall can be known theoretically.

$$
\begin{aligned}
& P_{r x}=P_{t x} G_{t x} G_{r x}\left(\frac{c}{4 \pi D_{r} f_{o}}\right)^{2} \\
& P_{r x}(d B)=P_{t x}+G_{t x}+G_{r x}+20 \log _{10}\left(\frac{\lambda}{4 \pi D_{r}}\right)
\end{aligned}
$$

where:

$P_{r x}$ is the power at the receiving antenna,

$P_{t x}$ is the output power at the transmitting antenna,

$G_{t x}$ is the gain of the transmitting antenna,

$G_{r x}$ is the gain of the receiving antenna,

$\lambda$ is the signal wavelength (in meters),

$D_{r}$ is the distance between two antennas,

$c$ is the speed of light in vacuum, $2.99792457 \times 10^{8}$ meters per second, and

$f_{o}$ is the signal frequency (in Hertz).

\subsubsection{Design of Multi-Band Dipole Antenna}

The geometric and excitation parameter of the antennas are depending on the design. The antenna geometric characteristics such as beam width and main-lobe to sidelobe power ratio can be described by the mathematical expressions of radiation patterns [14]. Geometric parameters that need to be specified when modelling a multi-band dipole antenna are thickness, width and length. Firstly, the value of the microstrip feed line width need to be estimated to ensure that the input impedance of the antenna is equal to $50 \mathrm{Ohm}$ (ideal impedance value). The impedance calculation of the thin microstrip was performed in CST software and the setup is shown in Figure 1.

To calculate the impedance, the antenna thickness, dielectric constant of substrate and width of microstrip feed line values are required in the settings. The antenna thickness, the dielectric constant of substrate and width of microstrip feed line were set to be $1.7 \mathrm{~mm}, 4.4$ and 3.28 respectively. The best antenna input impedance calculated from the CST software was $49.96 \mathrm{Ohm}$, which is very close to $50 \mathrm{Ohm}$. Thus, the antenna was modeled with 1.7 $\mathrm{mm}$ thickness.

To calculate the impedance, the antenna thickness, dielectric constant of substrate and width of microstrip feed line values are required in the settings. The antenna thickness, the dielectric constant of substrate and width of microstrip feed line were set to be $1.7 \mathrm{~mm}, 4.4$ and 3.28 respectively. The best antenna input impedance calculated from the CST software was $49.96 \mathrm{Ohm}$, which is very close to $50 \mathrm{Ohm}$. Thus, the antenna was modeled with 1.7 $\mathrm{mm}$ thickness.

As for the material properties, the microstrip was assigned with copper (annealed) material for the patches and ground parts. As for the substrate, which are located at the right and left parts of the antenna, Forgotten Realm 4 (FR-4) material was assigned to the parts. The value 
assigned to each design parameters of multi-band dipole antenna are presented in Table 1. The simulation results of multi-band dipole antenna are presented in 3-D and 2-D of radiation pattern and explained in Section 3.1.

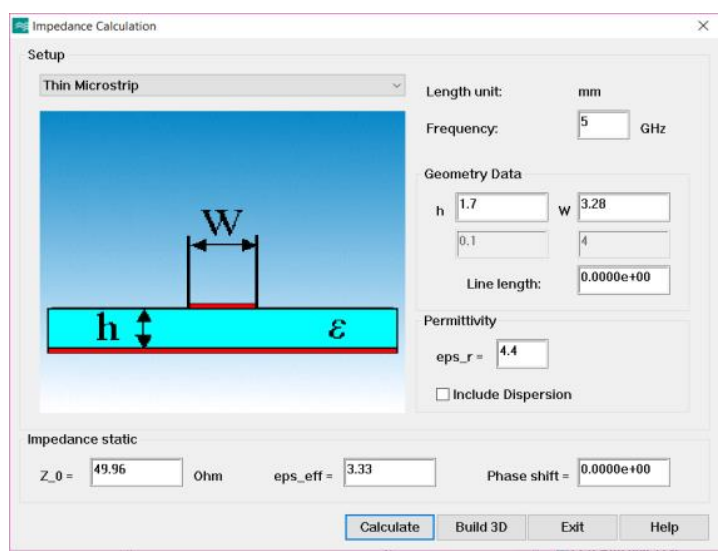

Figure 1. Calculation of impedance

Table 1. Design parameters of multi-band dipole antenna

\begin{tabular}{|l|l|l|}
\hline Parameters & Symbols & $\begin{array}{l}\text { Expression/ } \\
\text { Value }\end{array}$ \\
\hline Length of the fed line & $\mathrm{Fi}$ & 5.1 \\
\hline Gap between patch and inset fed & $\mathrm{Gpf}$ & 1 \\
\hline Length of antenna & $\mathrm{L}$ & 25 \\
\hline Ground length & $\mathrm{Lg}$ & $2 * \mathrm{~L}=50$ \\
\hline Width of antenna & $\mathrm{W}$ & 75 \\
\hline Ground width & $\mathrm{Wg}$ & $2 * \mathrm{~W}=150$ \\
\hline Height of conductor & $\mathrm{Ht}$ & 0.035 \\
\hline $\begin{array}{l}\text { Height of dielectric constant of } \\
\text { substrate }\end{array}$ & $\mathrm{Hs}$ & 1.7 \\
\hline Width of microstrip feed line & $\mathrm{Wf}$ & 3.28 \\
\hline
\end{tabular}

\subsubsection{Design of Single-Dipole Antenna}

The design parameters of the single-dipole antenna are shown in Table 2. Similar to types of materials used in [18], the Perfect Electric Conductor (PEC) was assigned for base and body parts and vacuum material assumption was assigned for the feed part. The simulation results of dipole antenna can be visualized in 3-D and 2-D of radiation pattern in Section 3.2.

Table 2. Dimension parameters of single-dipole antenna

\begin{tabular}{|l|c|c|}
\hline Parameters & Symbols & Value \\
\hline Radius of dipole & $\mathrm{R}$ & $2 \mathrm{~mm}$ \\
\hline Length of dipole & $\mathrm{L}$ & $62.46 \mathrm{~mm}$ \\
\hline Length of feed & $\mathrm{F}$ & $10 \mathrm{~mm}$ \\
\hline Input impedance & $\mathrm{Z}$ & $50 \mathrm{Ohm}$ \\
\hline
\end{tabular}

\section{RESULTS AND DISCUSSION}

In this section, the far field simulation results of singledipole and multi-band dipole antenna are presented and discussed based on the radiation pattern, Voltage Standing Wave Ratio (VSWR), gain and the directivity of the antenna. Antenna gain can be further used in Friis equation [15] to calculate the received power of the antenna. The total efficiency of an antenna design can also be obtained from simulation to evaluate the effectiveness.

\subsection{Simulation of Multi-Band Antenna}

To detect the RF transmission signal, the frequency ranges of RF signal to be detected must be acknowledged. Table 3 shows the frequency band of telecommunication signals that might present in the examination hall. Figure 2 shows the 3-D model of the multi-band dipole antenna constructed from design parameters listed in Table 1. The design of multiband dipole antenna was inspired from Siretta multiband antenna design.

To determine whether an antenna's port is having a significant signal strength, it can be known from the simulated S-parameter. Figure 3 indicates the S-parameter of multi-band dipole antenna. The relative strengths of reflected and transmitted signals at the port is described by the relationship between port 1 's incident signal $\mathrm{V}_{1}^{+}$and port 1 's resulting reflected signal $\mathrm{V}_{1}^{-}$: $\mathrm{s}_{11}=\mathrm{V}_{1}{ }^{-} / \mathrm{V}_{1}{ }^{+}$. For 1.9 $\mathrm{GHz}$ frequency band, the $\mathrm{S}$-parameter is $-9.184 \mathrm{~dB}$ while for $2.4 \mathrm{GHz}$ frequency band, S-parameter is $-10.701 \mathrm{~dB}$. In addition, the effectiveness of an antenna can be assessed based on the VSWR value. It indicates how well the antenna matched with the feed line, whether in transmission or receiver mode. As referred to Figure 4, the it shows satisfying VSWR value, approximately $2 \mathrm{~V}$, at frequency band of $0.8,2.1$ and $2.4 \mathrm{GHz}$, very close to ideal requirement which is below $2 \mathrm{~V}$.

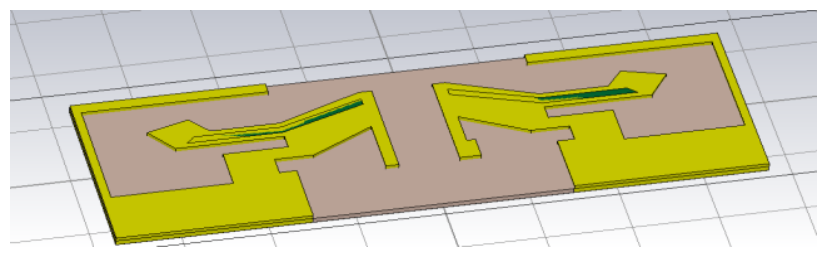

Figure 2. Multi-band dipole antenna model

Table 3. Frequency ranges of wireless communication

\begin{tabular}{|c|c|}
\hline $\begin{array}{c}\text { Type of Wireless } \\
\text { Communication }\end{array}$ & Frequency Band \\
\hline GSM/GPRS & $\begin{array}{c}850 \mathrm{MHz}, 900 \mathrm{MHz}, \\
1.8 \mathrm{GHz}, 1.9 \mathrm{GHz}\end{array}$ \\
\hline $3 \mathrm{G}$ & $1.9 \mathrm{GHz}, 2.1 \mathrm{GHz}$ \\
\hline $4 \mathrm{G}$ & $900 \mathrm{MHz}, 1.8 \mathrm{GHz}$ \\
\hline $\mathrm{ISM}$ & $868 \mathrm{MHz}, 2.4 \mathrm{GHz}$ \\
\hline
\end{tabular}




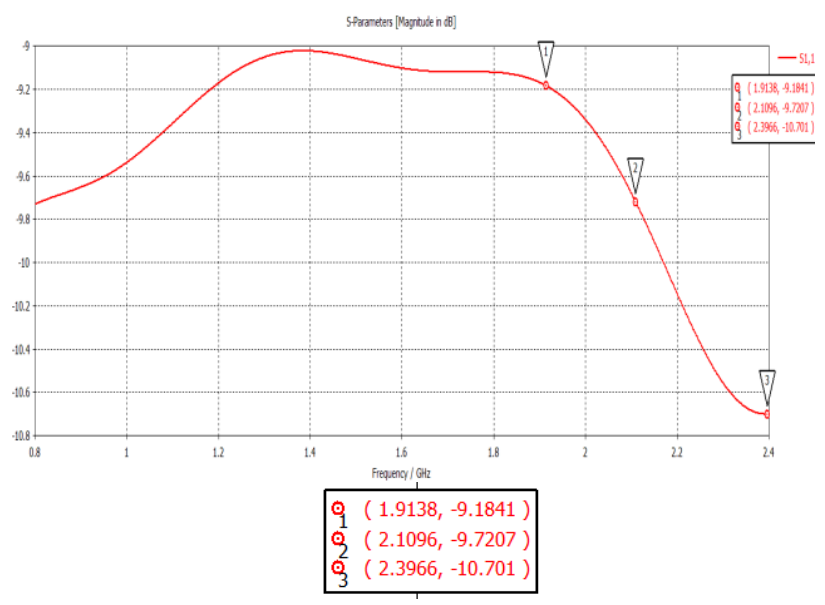

Figure 3. Simulated S-parameter measurement of multi-band dipole antenna

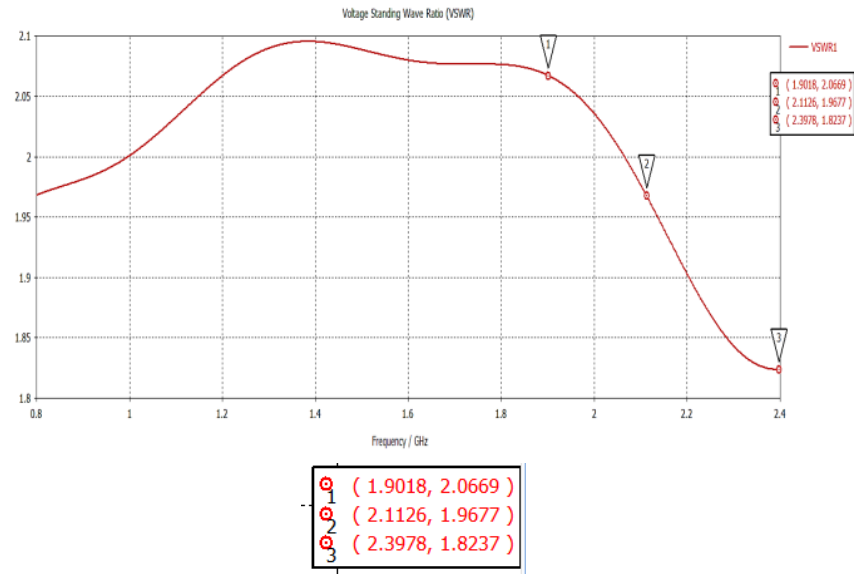

Figure 4. Simulated VSWR measurement of multiband dipole antenna

The radiation pattern of an antenna represents a graphical mathematical function as a function of space coordination. The area of the pattern where most of the radiation is directed is called the main lobe, while the side lobes are usually separated by an area of little radiation called nulls. From a radiation pattern results obtained from far-field simulation, the efficiency of the antenna design can be acknowledged from gain and directivity.

Based on Figures 5, 6, 7 and 8, the gain, directivity and total efficiency of multi-band dipole antenna are shown and are tabulated in Table 4. The gain value that is more than $2 \mathrm{~dB}$ is suitable for RF signal detection. The value can be used to calculate the power received by the multi-band dipole antenna using the Friis equation, Equation (2).

\subsection{Simulation of Dipole Antenna}

The 3-D view of a dipole antenna modeled and simulated in CST software is shown in Figure 9. Referring to Figure 10 , for $1.9 \mathrm{GHz}$ frequency band, the obtained S-parameter is $-8.7318 \mathrm{~dB}$ while for $2.4 \mathrm{GHz}$ frequency band, the obtained S-parameter is $-11.221 \mathrm{~dB}$.

In Figure 11, three out of five frequency band pinpointed VSWR more than $2 \mathrm{~V}$, considered impractical value. The radiation pattern of the dipole antenna in Figures 12 shows omnidirectional pattern, known as a doughnut-shaped radiation pattern. The power radiated is maximum in horizontal directions, dropping to zero directly above and below the antenna.

The 2-D radiation pattern of the dipole antenna are shown in Figure 13 to 15. It can be seen that the main lobe magnitude of $1.43 \mathrm{~dB}$ is gained for $1.9 \mathrm{GHz}$ frequency, 1.9 $\mathrm{dB}$ for $2 \mathrm{GHz}$ and $1.94 \mathrm{~dB}$ for $2.4 \mathrm{GHz}$, which the observed values are all less than $2 \mathrm{~dB}$, lower than multi-band dipole antenna gain.

The total efficiency of the dipole antenna at each frequency range signal as in Table 5, are also lower than the total efficiency shown by multi-band dipole antenna.

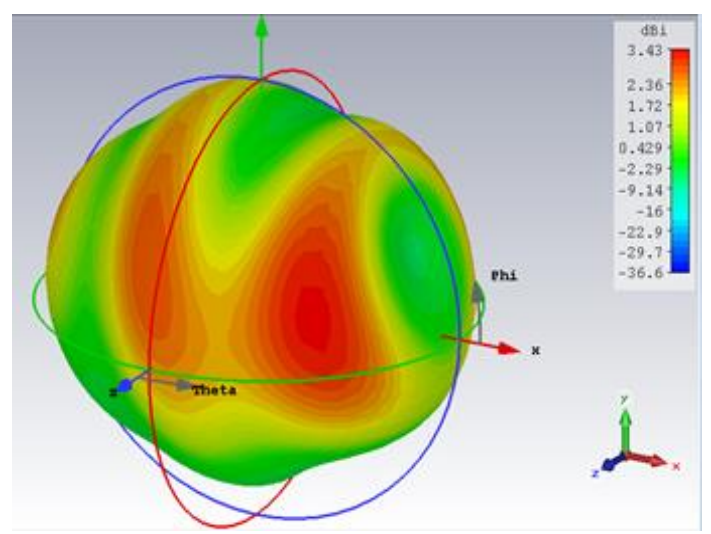

Figure 5. Simulated 3-D radiation pattern of multiband dipole antenna for $2.4 \mathrm{GHz}$

Table 4. Total efficiency of Multi-band dipole antenna

\begin{tabular}{|c|c|c|c|}
\hline $\begin{array}{c}\text { Frequency } \\
(\mathrm{GHz})\end{array}$ & $\begin{array}{c}\text { Gain } \\
(\mathrm{dB})\end{array}$ & Directivity(dBi) & $\begin{array}{c}\text { Total } \\
\text { Efficiency } \\
(\mathrm{dB})\end{array}$ \\
\hline 1.9 & 1.2 & 2.988 & 3.030 \\
\hline 2.1 & 2.38 & 3.182 & 3.183 \\
\hline 2.4 & 2.85 & 3.431 & 2.485 \\
\hline
\end{tabular}

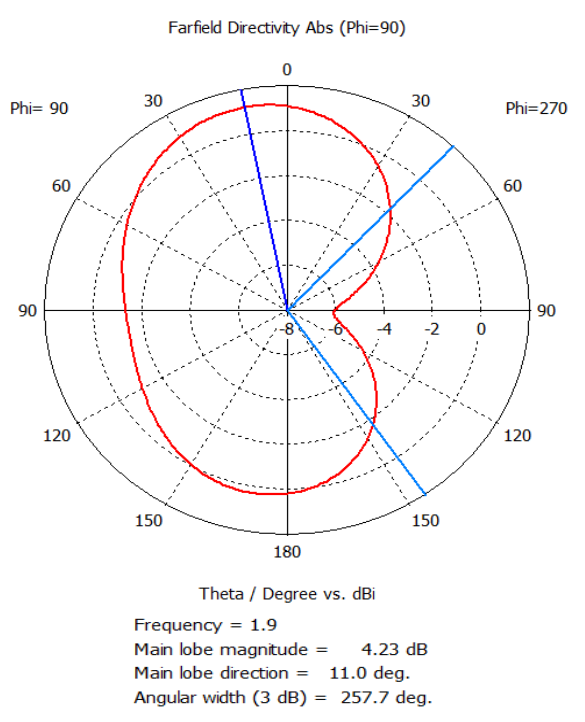

Figure 6. Simulated 2-D radiation patterns for multiband dipole antenna at $1.9 \mathrm{GHz}$ 


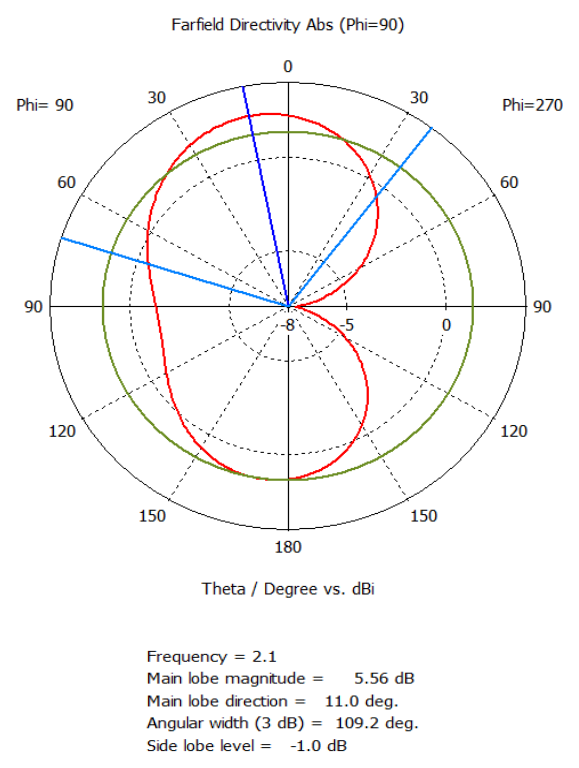

Figure 7. Simulated 2-D radiation patterns for multiband dipole antenna at $2.1 \mathrm{GHz}$

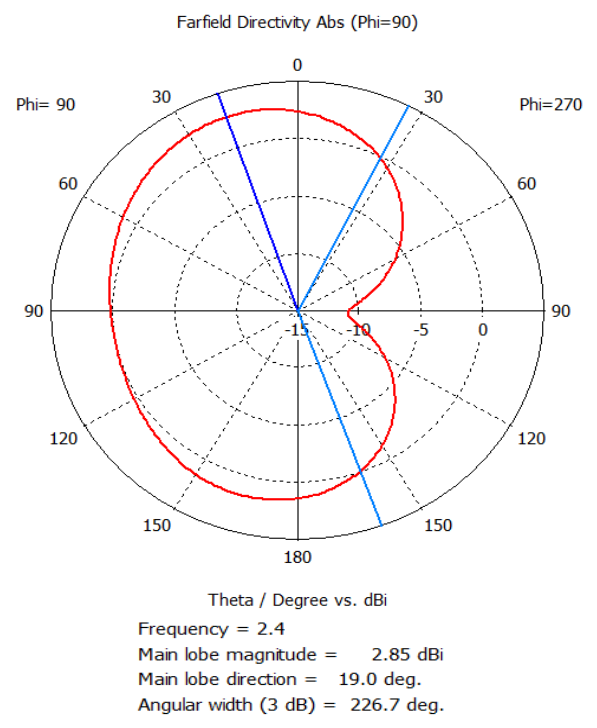

Figure 8. Simulated 2-D radiation patterns for multiband dipole antenna at $2.4 \mathrm{GHz}$

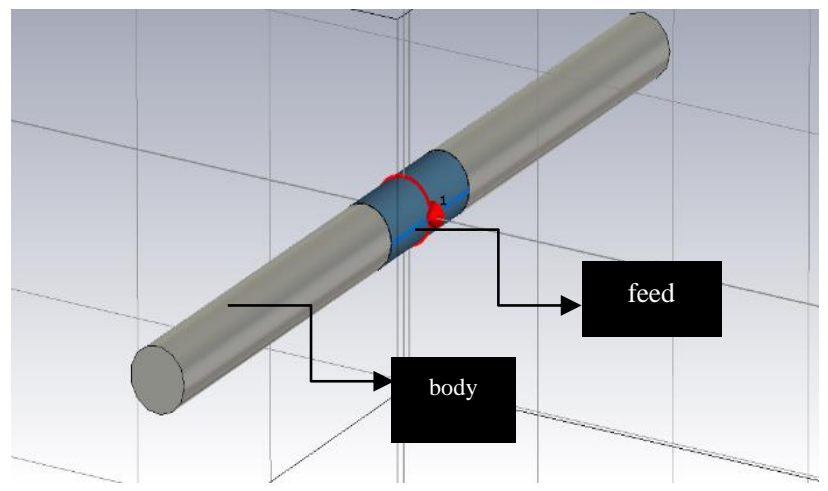

Figure 9. Simulated model of dipole antenna

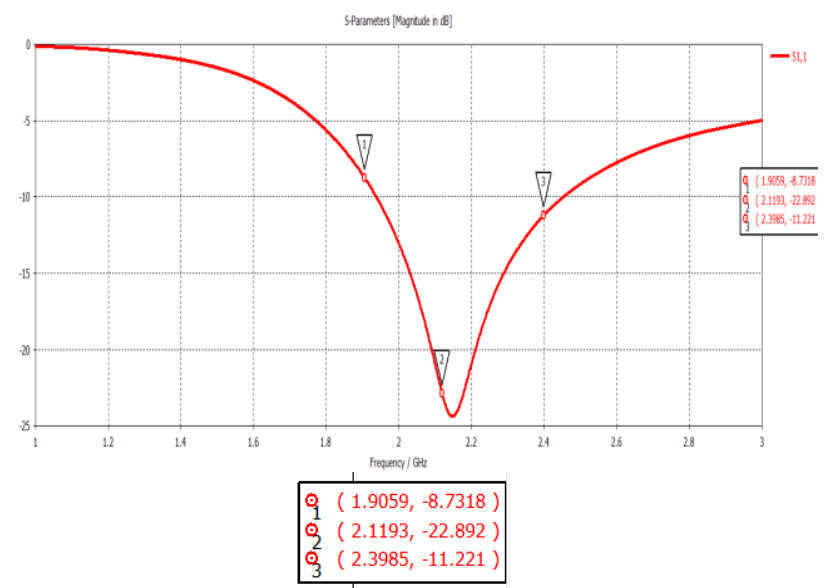

Figure 10. S-parameter of dipole antenna

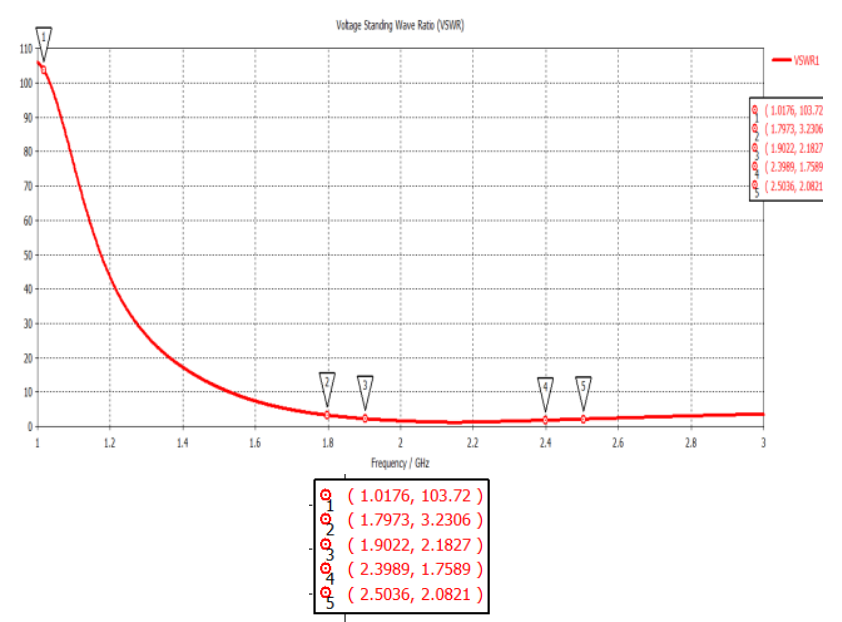

Figure 11. Simulated VSWR of single-dipole antenna

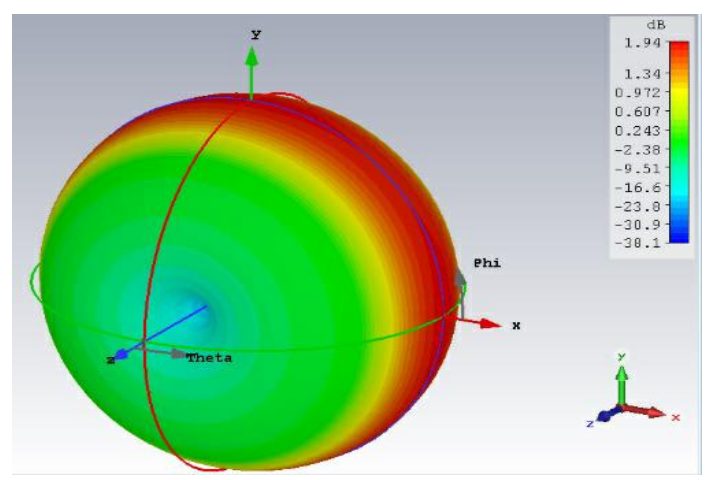

Figure 12. Simulated 3-D radiation pattern of singledipole antenna for $2.4 \mathrm{GHz}$

Table 5. Total efficiency of single-dipole antenna

\begin{tabular}{|c|c|c|c|}
\hline $\begin{array}{c}\text { Frequency } \\
(\mathrm{GHz})\end{array}$ & $\begin{array}{c}\text { Gain } \\
(\mathrm{dB})\end{array}$ & $\begin{array}{c}\text { Directivity } \\
(\mathrm{dBi})\end{array}$ & $\begin{array}{c}\text { Total Efficiency } \\
(\mathrm{dB})\end{array}$ \\
\hline 1.9 & 1.432 & 2.100 & -0.6676 \\
\hline 2.1 & 1.900 & 2.125 & -0.2243 \\
\hline 2.4 & 1.943 & 2.296 & -0.3529 \\
\hline
\end{tabular}




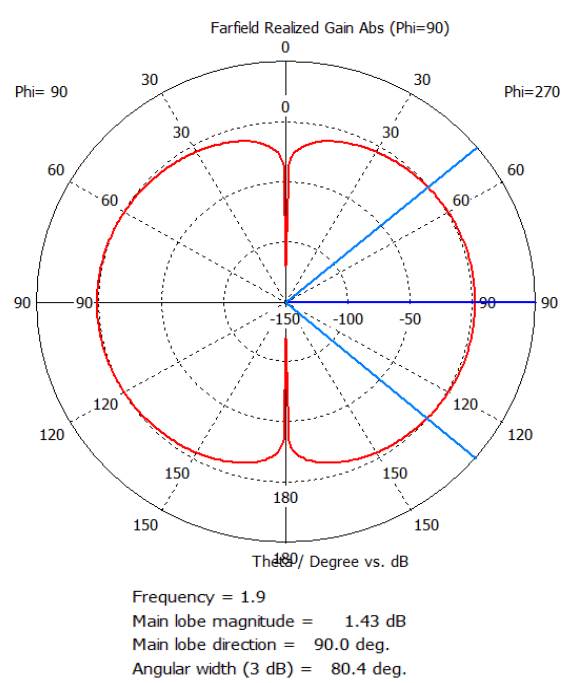

Figure 13. Simulated 2-D radiation pattern of singledipole antenna for $1.9 \mathrm{GHz}$

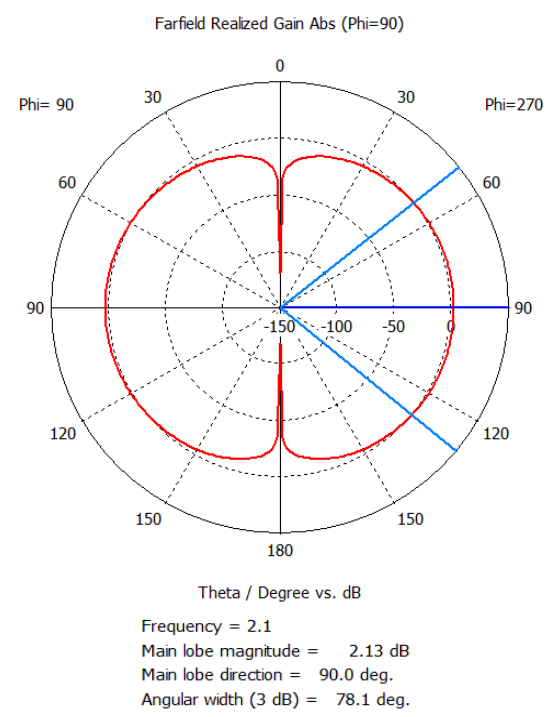

Figure 14. Simulated 2-D radiation pattern of singledipole antenna for $2.1 \mathrm{GHz}$

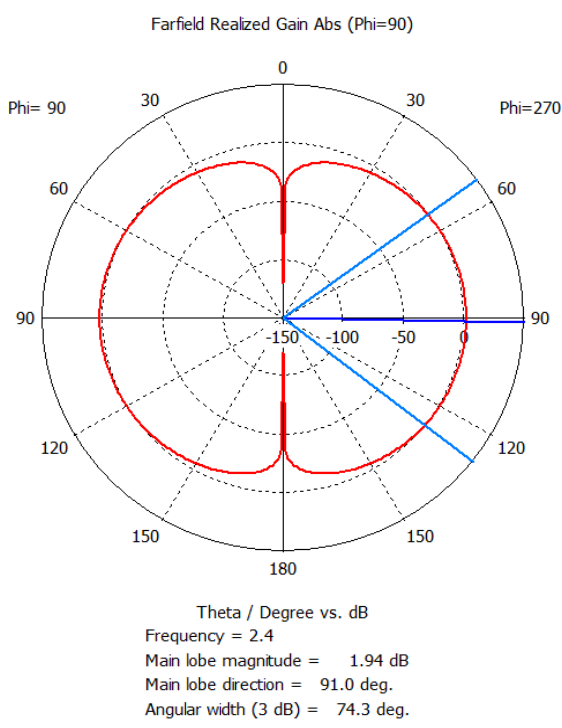

Figure 15. Simulated 2-D radiation pattern of singledipole antenna for $2.4 \mathrm{GHz}$

\section{CONCLUSION}

In conclusion, multi-band dipole antenna shows better ability to detect multiple ranges of radio frequency signal that come from mobile phone compared to single-dipole antenna. The multi-band dipole antenna's VSWR at tested frequency bands were approximately $2 \mathrm{~V}$, which is excellent in matching loads impedance to a transmission line. It also shows gain value more than $2 \mathrm{~dB}$ which is suitable to be used as a receiver. On the other hand, the basic single-dipole antenna can efficiently detect a single frequency band. If the single-dipole antenna is adopted in the detection system, several single-dipole antennas of different lengths are required in the detection circuit to serve the same purpose which will make the system sizable. In the future, the multi-band dipole antenna design prototype will be couple to RF signal detection circuit to analyze the RF signal receiving characteristics and to verify the effectiveness of the antenna in catching RF signal transmission.

\section{ACKNOWLEDGMENT}

This research is fully supported by Ministry of Education Malaysia and the Office of Research, Innovation, Commercialization, Consultancy Management (ORICC), Universiti Tun Hussein Onn Malaysia under the Tier 1 grant (Vot. No. H121).

\section{REFERENCES}

[1] D. S. Madara and S. S. Namango, "Faculty Perceptions on Cheating in Exams in Undergraduate Engineering," Journal of Education and Practice, vol. 7, no. 30, pp. 1-17, 2016.

[2] S. A. Shariffuddin and R. J. Holmes, "Cheating in Examinations : A Study of Academic Dishonesty in a Malaysian College," Asian J. Univ. Educ., vol. 5, no. 2, pp. 99-124, 2009.

[3] C. C. Mbaocha, "Design and Implmentation of Intelligent Mobile Phone Detector," Academic Research International, vol. 3, no. 1, pp. 478-483, 2012.

[4] K. Singh, M. Singh, and N. Gupta, "Design and Implementation of Cell-Phone Detection based Line follower Robot," Int. J. Electron. Comput. Sci. Eng., vol. 1, no. 3, pp. 1362-1368, 2014.

[5] E. Ataro, D. Starovoytova, and M. S. Sitati, "Design and Testing of Mobile-Phone-Detectors," Online), vol. 7, no. 9, pp. 2222-1727, 2016.

[6] S. I. Akaranga and Pj. J. Ongong, "The Phenomenon of Examination Malpractice : An Example of Nairobi and Kenyatta Universities," J. Educ. Pract., vol. 4, no. 18, pp. 87-97, 2013.

[7] R. Bawarith, A. Basuhail, A. Fattouh, and S. GamalelDin, "E-exam Cheating Detection System," IJACSA Int. J. Adv. Comput. Sci. Appl., vol. 8, no. 4, pp. 176181, 2017.

[8] A. Mehta, "Microstrip Antenna," International Journal of Scientific \& Technology Research, vol. 4, no. 3, pp. 54-57, 2015.

[9] M. Zhang, "A Novel Dual-Band Planar Monopole Mobile Phone Antenna for TD-LTE and TD-SCDMA Applications," $4^{\text {th }}$ International Conference on Systems and Informatics (ICSAI), pp. 906-910, 2017. 
[10] O. Eriksson and C. Lindh, "Designing a GSM Dipole Antenna," TNE 062 - RF System Design Course, pp. 1-19, 2008.

[11] A. Clemente, C. Delaveaud, and L. Rudant, "Analysis of Electrical Dipole Linear Array Maximum Directivity," $9^{\text {th }}$ European Conference on Antennaas and Propagation (EuCAP), vol. 1, no. 1, pp. 1-5.

[12]R.K. Raj, M. Joseph, B. Paul and P. Mohanan, "Compact Planar Multiband Antenna for GPS, DCS, 2.4/5.8 GHz WLAN Applications," Electronics Letters, vol. 41, no. 6, pp. 1-3, 2005.

[13] Q. Xue, C. H. Chan, and W. Communications, "MultiBand Printed Dipole Antenna using CRC Structure,", IEEE Antennas and Propagation Society International Symposium. Digest. Held in conjunction with: USNC/CNC/URSI North American Radio Sci. Meeting (Cat. No. 03CH37450), vol. 3, pp. 40-43.

[14] A. K. Srivastava, N. Pandey, and K. N. Singh, "Comparative Study of Radiation Pattern of Some
Different," International Journal of Physics and Applications, vol. 6, no. 2, pp. 109-114, 2014.

[15] M. Shahpari, D. V Thiel, "Fundamental limitations for antenna radiation efficiency," IEEE Transactions on Antennas and Propagation, vol. 66, no. 8, pp. 38943901, 2018.

[16] A. P. Junfithrana, E. T. Rahardjo, and F. Y. Zulkifli, "Development of Automated Antenna Radiation Pattern Measurement Using Rotator Application Model to Increase Accuracy," International Conference on Computing, Engineering and Design (ICCED), pp. 1-5, 2017.

[17] Pudu Atchutarao, "Design and Analysis of Antennas operating at different frequency bands using CST," Ph.D. dissertation, Dept. Elect. Eng., National Institute of Technology, Rourkela, India., 2015.

[18]H. Lin and C. Tang, "Analysis and Design for Highgain Antenna with Periodic Structures," Piers Online, vol. 6, no. 2, pp. 181-184, 2010. 